\title{
Opsonic and Protective Activity of Immunoglobulin, Modified Immunoglobulin, and Serum against Neonatal Escherichia coli K1 Infection
}

\author{
ROBERT BORTOLUSSI AND GERALD W. FISCHER \\ Infection and Immunology Research Laboratory, Izaak Walton Killam Hospital for Children, Dalhousie \\ University, Halifax, Canada [R.B.] and Uniformed Services University of the Health Sciences, F. Edward Hébert \\ School of Medicine, Bethesda, Maryland 20814-4799 [G.W.F.]
}

\begin{abstract}
Because modified immune serum globulin (M-ISG) has been proposed for therapy in neonatal bacterial sepsis, we evaluated it in a suckling rat model of Escherichia coli $\mathrm{K} 1$ sepsis. We compared a M-ISG preparation (lot 2581), which was protective against group B streptococcal (GBS) sepsis, with other M-ISG, standard ISG preparations and with adult and cord serum. All immune serum preparations and sera demonstrated opsonic activity against $E$. coli $\mathrm{K1}$ and were superior to saline in protecting against death due to $E$. coli $\mathrm{K} 1$ sepsis. Survival rates were higher for one M-ISG preparation (lot 2581) than for randomly selected standard immune serum globulin and cord sera but were similar to adult sera in these protection studies. Therapeutic and opsonic activity of standard immune serum globulin and M-ISG prepared from the same donors were similar, suggesting that the different processes used for their manufacture did not affect these activities. Because the M-ISG preparation studied showed protective activity to both GBS and $E$. coli $\mathrm{K} 1$, we studied it further by adsorbing the preparation with GBS and $E$. coli $\mathrm{K} 1$. Opsonic activity to $E$. coli $\mathrm{K} 1$ was removed by $E$. coli adsorption but not by adsorption with GBS, indicating that this activity was not due to a single crossreacting antibody. Empirical therapy with M-ISG prescreened for opsonic activity to both $E$. coli $\mathrm{K} 1$ and GBS may be of clinical value. Trials appear warranted to study the pharmacology and efficacy of M-ISG in septic newborns. (Pediatr Res 20: 175-178, 1986)
\end{abstract}

\section{Abbreviations}

CL, chemiluminescence

GBS, group B streptococcus

HBSS, Hanks' balanced salt solution

M-ISG, modified immune serum globulin

S-ISG, standard immune serum globulin

PMNs, Polymorphonuclear leukocytes

Strains of Escherichia coli which have a K1 capsular antigen are important causes of sepsis and meningitis among newborn

Received January 23, 1985; accepted October 7, 1985

Reprints requests R. Bortolussi, M.D., Infection and Immunology Research Laboratory, I. W. Killam Hospital, 5850 University Avenue, Halifax, Nova Scotia, Canada B3J 3G9.

Supported in part by the Medical Research Council of Canada Grant 210 and MA 7610 . R.B. is supported by a grant from the Medical Research Council of Canada infants (1). Although E. coli $\mathrm{K} 1$ isolates are usually susceptible to antibiotics in common use, morbidity and mortality remain high (2). This, plus the rapid progression from mild signs of infection to shock and even death suggest that immunity to the organism is insufficient in newborns. The fulminant course despite aggressive support techniques has led pediatricians to search for alternate approaches of treatment.

Studies from several laboratories have established that humoral antibody is crucial for resistance to infection due to encapsulated E. coli (3-7). Phagocytosis and killing of E. coli $\mathrm{Kl}$ by neutrophils requires the presence of both complement and antibody (4). Opsonic antibody is present in both $\operatorname{IgG}$ and $\operatorname{IgM}$ fractions of immune serum and has been shown to prevent death after $E$. coli $\mathrm{K} 1$ injection in suckling rats and in adult mice $(1,7,8)$. Since serum from newborn infants may have decreased opsonic activity for $E$. coli (9), these reports suggest that administration of immunoglobulin or serum having good opsonic activity against $E$. coli $\mathrm{K} 1$ will enhance neonatal resistance to infection with this organism.

Fischer, Wilson and Hunter reported enhanced opsonic and protective activity against GBS infection in suckling rats using a human M-ISG which is suitable for intravenous administration (10). If this material was also protective against $E$. coli $\mathrm{K} 1$ infection, it would have greater potential clinical value since these two organisms are the leading bacterial pathogens for newborn infants. We, therefore, studied the opsonic and protective activity of M-ISG, S-ISG and heat inactivated human serum against $E$. col $\mathrm{K} 1$ infection. The M-ISG preparation (lot 2581) used in the study is the same preparation reported previously by Fischer et al. (10), to provide protection against GBS.

\section{MATERIALS AND METHODS}

Bacteriological methods. The E. coli strain, serotype 018ac:K1:H7, was isolated from the cerebrospinal fluid of an infant with meningitis. Dynamics of infection in suckling rats (11) and characteristics of opsonic requirements, capsular K1 production and virulence of this strain have been reported previously (12). The organism was grown to mid-log phase in brain heart infusion broth (Difco Laboratories, Detroit, $\mathrm{MI}$ ) and stored in aliquots at $-70^{\circ} \mathrm{C}$ with $20 \%$ glycerol. For each in vivo or in vitro study one of the aliquots was thawed and used to inoculate fresh brain heart infusion broth. The organism was grown to mid-log phase and the bacterial concentration was estimated spectrophotometrically as described previously (11). Pour plates with brain heart infusion agar were used to confirm the estimate of bacterial content.

Animal experiments. Protection studies were done using a 
suckling rat model of $E$. col $i \mathrm{~K} 1$ sepsis (11). Five-day-old SpragueDawley rats (Charles River Laboratories, Montreal, Canada) were injected subcutaneously with $0.1 \mathrm{ml}$ (approximately $5 \times$ $10^{3}$ colony forming units) of a mid-log phase $E$. coli $\mathrm{K} 1$ suspension caudal to the neck. At various times after bacterial injection, the animals were given an intraperitoneal injection with $0.2 \mathrm{ml}$ of either the M-ISG, S-ISG, or serum preparation. Each subject's serum or each S-ISG lot was injected into five animals for each study time. The M-ISG preparation was tested in an identical manner except that lot 2581 of the M-ISG preparation was injected into 15 animals for study times at 5 and $30 \mathrm{~min}$ and at 10 animals for study times 120 and $240 \mathrm{~min}$. Controls consisted of litter mates treated with an intraperitoneal injection of $0.2 \mathrm{ml}$ of saline $(0.85 \mathrm{~g} / \mathrm{dal} \mathrm{NaCl})$. All animals were observed daily for 5 days to determine the percent survival.

Opsonophagocytosis. Leukocytes were separated by dextran sedimentation from heparinized venous blood obtained from adult volunteers as described previously (13). Cells were washed twice in HBSS (Grand Island Biological Co., Grand Island, NY) then suspended in a hypotonic ammonium chloride solution $\left(0.155 \mathrm{M} \mathrm{NH}_{4} \mathrm{Cl}+10 \mathrm{mM} \mathrm{KHCO} 3\right)$ to lyse the red blood cells. After further washing, leukocytes were suspended in HBSS to a concentration of $1 \times 10^{6}$ polymorphonuclear leukocytes $/ \mathrm{ml}$ (PMNs/ml).

E. coli $\mathrm{K} 1$ (approximately $10^{8}$ colony forming units $/ \mathrm{ml}$ ) were opsonized by adding M-ISG, S-ISG, or heat-inactivated serum $\left(56^{\circ} \mathrm{C}\right.$ for $\left.30 \mathrm{~min}\right)$ and an equal volume of adsorbed human serum (adsorbed at $4^{\circ} \mathrm{C}$ with the test strain and stored in aliquots at $-70^{\circ} \mathrm{C}$ ) as the source of complement. A serum concentration of $1.5 \%$ and M-ISG and S-ISG dilutions of $1 / 80$ were chosen after dose-response experiments showed these concentrations to be optimal for demonstrating differences in opsonic activity between sera. The bacteria-serum mixtures were rotated endover-end at $37^{\circ} \mathrm{C}$ for $30 \mathrm{~min}$. Bacteria were sedimented by centrifugation, washed three times in phosphate-buffered saline, then resuspended to their original volume in HBSS.

Opsonic activity was estimated using a luminol enhanced CL technique similar to the method described by Stevens and Young (5). Measurements were made using a Nuclear Chicago Mark II Scintillation Counter adjusted out-of-coincidence. A mixture of $1 \times 10^{6}$ PMNs $(1.0 \mathrm{ml})$ and $4 \times 10^{7}$ colony forming units of opsonized bacteria $(0.4 \mathrm{ml})$ was added to $3 \mathrm{ml}$ of HBSS containing $10^{-7} \mathrm{M}$ luminol (Sigma Chemical Co., St. Louis, MO) in a disposable scintillation vial. Scintillation counts were recorded at 5 -min intervals for $60 \mathrm{~min}$. Opsonic activity was estimated by calculating the area of the curve formed by the plot of counts against time. Background CL, obtained by using unopsonized bacteria mixed with PMNs was subtracted from the result using opsonized organisms. All samples were done in duplicate.

Immunoglobulin preparations. Studies were done using several lots of M-ISG and S-ISG. Two lots of M-ISG $(2581,10 \% \mathrm{IgG}$ and $2662,5 \% \mathrm{IgG}$ ) were kindly supplied by Cutter Laboratories, Inc., Berkeley, CA S-ISG (16.5\% IgG), obtained from Cutter Labs (lots 2591 and 2021) and Connaught Laboratories, Ltd., Toronto, Canada (lots 7036, 7018 and 7031), were diluted to $10 \% \mathrm{IgG}$ for in vivo studies. The two S-ISG lots provided by Cutter Laboratories were obtained from the same donor pools as the two M-ISG lots (lot 2581 same as lot 2591, lot 2662 same as lot 2021). In some experiments M-ISG was adsorbed with $E$. coli $\mathrm{K} 1$ or GBS. This was done by mixing three volumes of $\mathrm{M}$ ISG with one volume of packed bacteria. After vortexing to resuspend bacteria, the mixture was tumbled end-over-end for 2 $\mathrm{h}$ at $4^{\circ} \mathrm{C}$. Bacteria were sedimented by centrifugation and serum was decanted. The procedure was repeated once.

Serum was obtained from the following groups of individuals who were not receiving antibiotics at the time of donating blood: patients with cystic fibrosis (five subjects), cord human blood (12 subjects), and normal adult controls (four subjects). For comparison, serum obtained from a rabbit immunized with the homologous E. coli $\mathrm{Kl}$ stain was also studied. In the animal protection study, human serum and M-ISG and S-ISG were not diluted before administration while the rabbit immune serum was diluted $1: 10$ in saline before it was given to animals.

\section{RESULTS}

Figure 1 shows the results of experiments in which various immunoglobulin and serum preparations were tested for their ability to protect 5 -day-old neonatal rats from $E$. coli $\mathrm{K} 1$ sepsis and death. Five-day survival in controls receiving saline was $5 / 36(14 \%)$. Although human sera enhanced protection, it is of interest that sera collected from individuals with repeated infections due to gram-negative organisms, patients with cystic fibrosis, was no better at protecting animals from death than sera collected from controls ( 40 and $45 \%$ survival respectively at 5 days). Cord sera obtained from full-term infants was less effective at protecting animals ( $30 \%$ survival, $p>0.05$ versus saline) than was sera from normal adults (45\% survival, $p<0.05$ versus saline controls). By comparison, animals injected with immune rabbit serum diluted $1 / 10$ had greater protection $(60 \%$ survival, not shown on Fig. 1).

Table 1 shows survival when M-ISG (lot 2581), or S-ISG (three lots) or saline were given $5,30,120$, or 240 min after the animals were challenged with bacteria. Even if the M-ISG injection was delayed for $240 \mathrm{~min}$, animals were still protected (40\% survival versus $8 \%$ for saline controls). For S-ISG survival was 33 and $20 \%$ for animals injected at 5 and at $240 \mathrm{~min}$, respectively. Survival was best in all groups if the animals were treated within 5 min of infection.

M-ISG lot 2581 had previously been shown to provide opsonic and protective activity against GBS. To determine if the protective activity which we found for $E$. coli $\mathrm{K} 1$ might be due to opsonic antibody, we adsorbed this M-ISG lot with $E$. coli $\mathrm{K} 1$ and with GBS and assessed opsonic activity using a CL assay. As shown in Table 2, CL activity of M-ISG lot 2581 against $E$. coli $\mathrm{K} 1$ was markedly decreased if the preparation was adsorbed with E. coli $\mathrm{K} 1$, but only slightly lowered after adsorption with GBS Opsonization was poor in the absence of complement. M-ISG without complement had $50 \%$ less CL activity than M-ISG with complement.

In order to assess if the better survival observed with M-ISG compared to S-ISG was a result of the chance inclusion of serum from individuals with high antibody activity against the test strain in the M-ISG preparation but not in the S-ISG preparations, we assessed the CL and protective activity of M-ISG and S-ISG pairs made from the same pool of donors. In pair 1 (lot 2581 and 2591), the CL and protective activities were both high while in pair 2 (lot 2262 and 2021) the CL and protective activities were lower (Table 3). Since lot 2662 is a $5 \%$ IgG

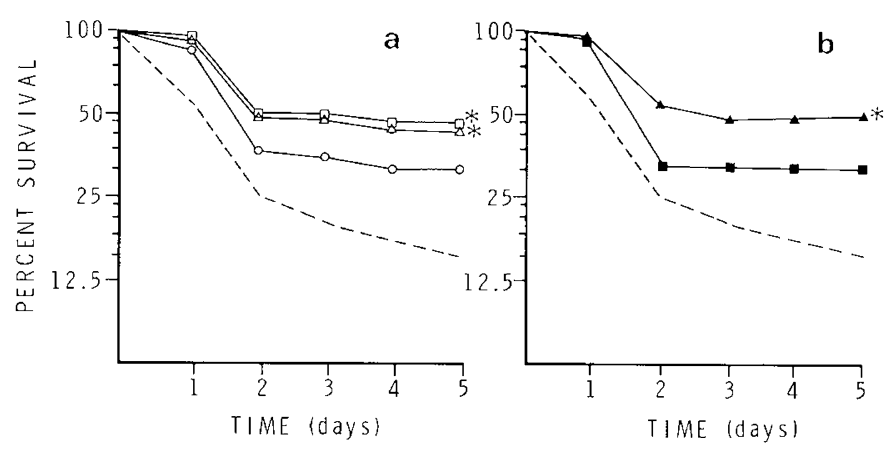

Fig. 1. Effect of various humoral preparations on suckling rat $E$. coll $\mathrm{K} 1$ infection: ( $a$ ) four control adult sera ( $\square, 20$ animals), sera from five subjects with cystic fibrosis $(\triangle, 25$ animals), sera from cord blood of 12 newborn infants $(O, 60$ animals); (b) M-ISG lot 2581 ( $\boldsymbol{\Delta}, 15$ animals), S-ISG ( $\boldsymbol{\square}, 3$ lots. 15 animals). Thirty-six control animals injected with saline are shown with broken lines. ${ }^{*} p<0.05$ compared to saline controls. 
Table 1. Protection of suckling rats with M-ISG over various times after bacterial challenge

\begin{tabular}{lcccc}
\hline & \multicolumn{4}{c}{ Time $(\mathrm{min})$ after bacterial challenge } \\
\cline { 2 - 5 } Preparation & $5 \mathrm{~min}$ & $30 \mathrm{~min}$ & $120 \mathrm{~min}$ & $240 \mathrm{~min}$ \\
\hline M-ISG (lot 2581) & $8 / 15(53)^{*}$ & $7 / 15(46)$ & $4 / 10(40)$ & $4 / 10(40)$ \\
S-ISG (3 lots) & $5 / 15(33)$ & $4 / 15(27)$ & $4 / 15(27)$ & $2 / 15(13)$ \\
Saline & $7 / 32(22)$ & $5 / 36(14)$ & $3 / 30(10)$ & $2 / 26(8)$ \\
\hline
\end{tabular}

* No animals alive 5 days after challenge over the number injected $(\%)$

Table 2. Opsonic activity of $M-I S G$ after adsorption with $E$. COLI KI or GBS

\begin{tabular}{lc}
\hline \multicolumn{1}{c}{ Preparation* } & Opsonic activity ${ }^{*}$ \\
\hline Pooled human serum & 9700 \\
M-ISG (lot 2581) & 9980 \\
M-ISG adsorbed with E. coli K1 & 980 \\
M-ISG adsorbed with GBS & 6600 \\
M-ISG without complement & 4900 \\
Complement only & 930 \\
\hline
\end{tabular}

* Each preparation for opsonic testing was mixed with serum adsorbed with $E:$ coli $\mathrm{Kl}$ as a source of complement, unless stated otherwise.

+ Opsonic activity expressed as the area of the curve formed by the counts rersus time was determined using a luminol enhanced chemiluminescence assay.

Table 3. Effect of M-ISG and S-ISG collected from identical donors on opsonic activity against $E$. COLI KI and on survival in a suckling rat model

\begin{tabular}{ccc}
\hline Preparation & Opsonic activity* & Survival $(\%) \dagger$ \\
\hline Pair 1 & & \\
M-ISG\$ & 9.980 & $8 / 15(53)$ \\
S-ISG\$ & 10.700 & $8 / 15(53)$ \\
& & \\
Pair 2 & & $4 / 15(27)$ \\
M-ISG\$ & 4.600 & $3 / 15(20)$ \\
S-ISG\$ & 6.800 & $1 / 15(6)$ \\
Saline & & \\
\hline
\end{tabular}

* Opsonic activity expressed as the area of the curve formed by counts versus time was determined using luminol enhanced chemiluminescence assay.

† Survival assessed 5 days after challenge with bacteria, for animals given various M-ISG. or S-ISG preparations subcutaneously $30 \mathrm{~min}$ after being injected intraperitoneally with $1 \times 10^{4}$ colony forming units of $E$. (o)li Kl.

t. M-ISG (lot 2581). S-ISG (lot 2591) collected from the same donor pool. See "Materials and methods" for IgG concentration.

$\$$ M-ISG (lot 2662). S-ISG (lot 2021) collected from the same donor pool. Sce "Materials and methods" for IgG concentration.

preparation, those animals received half of the $\operatorname{IgG}$ as the animals that received 2581. Opsonic activity of immunoglobulin preparations using the $\mathrm{CL}$ assay therefore correlated well with the protective activity of the immunoglobulin preparations using the suckling rat sepsis model.

\section{DISCUSSION}

The mortality rate for $E$. coli $\mathrm{K} 1$ meningitis remains at approximately $33 \%$ despite the use of newer more potent antibiotic and direct installation of antibiotics into cerebrospinal fluid (14). Because of this, several investigators have explored the possibility of using immunoglobulin therapy to prevent or modify neonatal sepsis. Studies by Fischer et al. $(10,15,16)$ and Santos of al. (17) have demonstrated that M-ISG preparations given to newborn rats protected the animals against the lethal effects of GBS infection. Furthermore, in each of these studies, protection correlated well with the in vitro opsonic activity of the immunoglobulin preparations.

Early in the course of human neonatal infections, it is not usually possible to determine with certainty the organism responsible for sepsis. Since GBS and $E$. coli $\mathrm{Kl}$ are the most common types of bacteria isolated from newborn infants with meningitis, we attempted to determine if similar beneficial effects of M-ISG observed with GBS would also occur with $E$. coli $\mathrm{K} 1$. In this experiment M-ISG (lot 2581 and 2662) used previously with GBS was employed as well as random lots of S-ISG and lots of S-ISG obtained from the same donors as lots 2581 and 2662. In our study, there was a good correlation between opsonic activity and the protective capacity of the immunoglobulin preparation. The 10 -fold reduction in $\mathrm{CL}$ activity after adsorption with $E$. coli $\mathrm{K} 1$, but not GBS, strongly suggests that the opsonic activity is due to $\operatorname{IgG}$ directed against an antigen or antigens on the $E$. coli. The protection afforded by M-ISG and S-ISG prepared from the same pool of donors was similar suggesting that further modification of the S-ISG by reduction and alkylation did not greatly reduce the opsonic and protective activity to $E$. coli $\mathrm{K} 1$.

Protection for all preparations was best when given very soon (5 min, Table 1) after the bacterial challenge and decreased steadily with further delay. By $4 \mathrm{~h}$ only the M-ISG preparation with good opsonic activity showed protection while the effect of various S-ISG preparations had disappeared. Protective capacity of M-ISG after $4 \mathrm{~h}$ was not assessed. For GBS infection Fischer et al. (10), Santos et al. (17), and Shigeoka et al. (18) found no benefit with M-ISG at times greater than 4 or $5 \mathrm{~h}$. Unexpectantly we found that saline administered 5 min after challenge had slight protective effect. Although this last observation did not reach statistical significance, it merits additional study.

Sera from normal adult controls and from subjects with cystic fibrosis were no better than the M-ISG preparation. The last group of subjects were included to determine if repeated exposure to gram-negative bacteria (Pseudomonas aeruginosa) might protect against neonatal $E$. coli $\mathrm{K} 1$ infection by inducing antibody to common gram-negative antigens such as core glycolipid. Although we failed to show any benefit, this question is not settled since anticore glycolipid was not measured. Of interest is the observation that sera from cord blood gave the poorest protection.

Our results, when taken together with those reported previously with M-ISG in animal models of GBS infection, suggest that M-ISG therapy may be of benefit in treating human newborn infections due to both GBS and E. coli K1. Empiric therapy prior to identification of the infecting bacteria may, therefore, be possible. It will be crucial, however, to screen the intravenous immunoglobulin lots for antibacterial opsonic activity, to ensure functional activity is present. Clinical trials in neonates may be warranted to analyze the ability of intravenous immunoglobulin to enhance neonatal immunity against bacterial diseases.

Acknowledgments. The authors acknowledge the aide of Miss N. Campbell for her technical assistance and Miss R. Sampson for typing the manuscript.

\section{REFERENCES}

1. Robbins JB, McCracken GH Jr, Gotschlich EC, Orskov F, Orskov I, Hanson LA 1974 Escherichia coli $\mathrm{K} 1$ capsular polysaccharide associated with nconatal meningitis. N Engl J Med 290:1216-1220

2. McCracken GH Jr, Sarff LD, Glode MP. Mize SG, Schiffer MS. Robbins JB. Gotschlich EC. Orskov I. Orskov F 1974 Relation between Escherichia coll $\mathrm{K} 1$ capsular polysaccharide antigen and clinical outcome in neonatal meningitis. Lancet 2:246-250

3. Van Dijk WC, Verbrugh HA, van Erne-van der Tol ME. Peters R. Verhoef J 1981 Excherichia coli antibodies in opsonization and protection against infection. J Med Microbiol 14:381-389

4. Stevens P. Huang S . .Y. Welch WD. Young LS 1978 Restricted complement 
activation by Escherichia coli with the K-I capsular serotype: a possible role in pathogenicity. J Immunol 12 1:2174-2180

5. Stevens P. Young LS 1977 Quantitative granulocyte chemiluminescence in the rapid detection of impaired opsonization of Escherichia coli. Infect Immun 16:796-804

6. Van Dijk WC. Verbrugh HA, Peters R, Van Der Tol ME, Peterson PK, Verhoef $\mathrm{J} 1979$ Escherichia coli $\mathrm{K}$ antigen in relation to serum-induced lysis and phagocytosis. J Med Microbiol 12:123-130

7. Ax W, Kanzy E-J. Seiler FR 1981 In vivo phagocytosis: Enhancement of bacterial clearance by native and enzyme-treated immunoglobulins. Immunobiol 159:349-359

8. Menzel J, Jungfer H, Gemsa D 1978 Contribution of immunoglobulins M and G. complement, and properdin the intracellular killing of Escherichia coli by polymorphonuclear leukocytes. Infect Immun 19:659-666

9. McCracken GH Jr, Eichenwald HF 1971 Leukocyte function and the development of opsonic and complement activity in the neonate. Am J Dis Child 121:120-125

10. Fischer GW, Wilson SR, Hunter KW Jr 1982 Functional characteristics of a modified immunoglobulin preparation for intravenous administration: summary of studies of opsonic and protective activity against group B streptococci. J Clin Immunol 2:31S-35S

11. Bortolussi R, Ferrieri P. Wannamaker LW 1978 Dynamics of Escherichia coli infection and meningitis in infant rats. Infect Immun 22:480-485
12. Bortolussi R, Ferrieri P, Bjorksten B, Quie PG 1979 Capsular K1 polysaccharide of Escherichia coli: relationship to virulence in newborn rats and resistance to phagocytosis. Infect Immun 25:293-298

13. LeBlanc CMA, Bortolussi R, Issekutz AC, Gillespie T 1982 Opsonization of mucoid and non-mucoid Psendomonas aeruginosa by serum from patients with cystic fibrosis assess by a chemiluminescence assay. Clin Invest Med $5: 125-128$

14. McCracken GH Jr, Mize SG, Threlkeld N 1980 Intraventricular gentamicin therapy in gram-negative bacillary meningitis of infancy. Report of the second neonatal meningitis cooperative study group. Lancet 1:787-79 I

15. Fischer GW, Hunter KW Jr, Wilson SR, Hensen SA 1980 In: Alving BM, Finlayson JS (eds) Immunoglobulins: Characteristics and Uses of Intravenous Preparations, vol. 1. Government Printing Office, Washington, DC, pp $81-88$

16. Fischer GW, Hunter KW Jr, Wilson SR 1982 Modified human immune serum globulin for intravenous administration: in vitro opsonic activity and in vivo protection against group B streptococcal disease in suckling rats. Acta Paediatr Scand 71:639-644

17. Santos JI, Shigeoka AO, Rote NS, Hill HR 1981 Protective efficacy of a modified immune serum globulin in experimental group B streptococcal infection. J Pediatr 99:873-879

18. Shigeoka AO, Pincus SH, Rote NS, Hill HR 1984 Protective efficacy of hybridoma type-specific antibody against experimental infection with groupB Streptococcus. J Infect Dis 149:363-372 